Article

\title{
Can Comprehensive Geriatric Assessment Predict Tolerance of Radiotherapy for Localized Prostate Cancer in Men Aged 75 Years or Older?
}

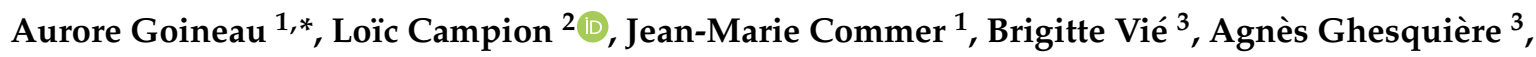 \\ Guillaume Béra ${ }^{4}$, Didier Jaffres ${ }^{4}$, Nicolas Magné ${ }^{5}$, Xavier Artignan ${ }^{6}$, Jérôme Chamois ${ }^{6}$, \\ Philippe Bergerot ${ }^{7}$, Gilles Créhange ${ }^{8}$, Elisabeth Deniaud-Alexandre ${ }^{9}$, Xavier Buthaud ${ }^{10}$, \\ Yazid Belkacémi ${ }^{11}$, Mélanie Doré ${ }^{12}$, Laure De Decker ${ }^{12}$ and Stéphane Supiot ${ }^{12}$ (D) \\ 1 Department of Radiation Oncology, Institut de Cancérologie de l'Ouest, 49000 Angers, France; \\ jean-marie.commer@ico.unicancer.fr \\ 2 Department of Statistics, Institut de Cancérologie de l'Ouest, CRCINA, University of Nantes, INSERM \\ UMR1232, CNRS-ERL6001, 44800 Saint Herblain, France; loic.campion@ico.unicancer.fr \\ 3 Department of Radiation Oncology, Clinique Armoricaine de Radiologie, 22000 St Brieuc, France; \\ b.vie@cario-sante.fr (B.V.); aghesquiere@ch-treguier.fr (A.G.) \\ 4 Department of Radiation Oncology, Centre Hospitalier de Bretagne Sud, 56100 Lorient, France; \\ g.bera@ch-bretagne-sud.fr (G.B.); d.jaffres@ch-bretagne-sud.fr (D.J.) \\ 5 Department of Radiation Oncology, Institut de Cancérologie de Loire, 42270 St Priest en Jarez, France; \\ nicolas.magne@icloire.fr \\ 6 Department of Radiation Oncology, CHP St Grégoire, 35760 St Grégoire, France; \\ xartignan@vivalto-sante.com (X.A.); jchamois@vivalto-sante.com (J.C.) \\ 7 Department of Radiation Oncology, Clinique Mutualiste de l'Estuaire, 44600 St Nazaire, France; \\ philippe.bergerot@mla.fr \\ 8 Department of Radiation Oncology, Centre Georges François Leclerc, 21000 Dijon, France; gcrehange@cgfl.fr \\ 9 Department of Radiation Oncology, Centre Hospitalier Départemental de Vendée, 85000 La Roche sur Yon, \\ France; elisabeth.deniaud-alexandre@chd-vendee.fr \\ 10 Department of Radiation Oncology, Centre Catherine de Sienne, 44000 Nantes, France; \\ xavier.buthaud@groupeconfluent.fr \\ 11 Department of Radiation Oncology, CHU Henri Mondor, 94000 Créteil, France; yazid.belkacemi@aphp.fr \\ 12 Department of Radiation Oncology, Institut de Cancérologie de l'Ouest, 44800 Saint Herblain, France; \\ melanie.dore@ico.unicancer.fr (M.D.); laure.dedecker@ico.unicancer.fr (L.D.D.); \\ stephane.supiot@ico.unicancer.fr (S.S.) \\ * Correspondence: aurore.goineau@ico.unicancer.fr; Tel.: +33-241-352-915; Fax: +33-241-2-735
}

Received: 31 January 2020; Accepted: 3 March 2020; Published: 9 March 2020

check for updates

\begin{abstract}
Curative radiotherapy for prostate cancer is common in the elderly. However, concerns about potential toxicity have inhibited access to radiotherapy for this population, for whom preserving quality of life (QoL) is crucial. The primary endpoint was to identify predictors of impaired QoL in men aged 75 years or older treated with curative intent radiotherapy with or without androgen deprivation therapy (ADT) for localized prostate cancer. We prospectively performed comprehensive geriatric assessment (CGA) and administered QoL questionnaires to 208 elderly ( $>75$ years) patients prior to, plus two and six months after, radiotherapy (NCT 02876237). The median age of the patients was 77 years (range 75-89). At the start of the study, comorbidities were highlighted in 65\% of patients: $23 \%$ were depressed, $23 \%$ had cognitive impairment, and 16\% had reduced independence. At six months, $9 \%$ of patients had a consistently decreased QoL ( $>20$ points), and a further $16 \%$ had a more moderate reduction (10 to 20 points) in QoL. None of the parameters studied (tumor characteristic, treatment, or oncogeriatric parameters) were predictive of a reduced QoL following radiotherapy. Though co-existing geriatric impairment was common, QoL was maintained for 75\% of patients six months after radiotherapy. CGA was poorly predictive of tolerance of prostatic radiotherapy. Geriatric assessments dedicated to quality of life following radiotherapy need to be developed.
\end{abstract}


Keywords: prostate cancer; radiotherapy; quality of life; toxicity; comprehensive geriatric assessment; geriatric rating scales

\section{Introduction}

Incidence of prostate cancer is on the increase in Western countries, especially in the elderly, and determining the best treatment to offer this heterogeneous population is a challenging issue. Quality of life (QoL) is key in this group of patients, and the potential toxicity of radiotherapy is a major concern, both for patients and the physicians advising them. Moreover, comorbidities or impaired urinary, digestive, or geriatric functions are more frequent in the elderly and may worsen after radiotherapy. Palliative treatment (androgen deprivation therapy (ADT) or no therapy at all) is thus offered to most patients over the age of 75 years with localized high-risk prostate cancer [1], despite the proven improvement in survival induced by radiotherapy [2].

We chose to evaluate early quality of life after radiotherapy because we have previously shown, in a younger population, that there is a temporary decrease in QoL after intensity-modulated radiation therapy (IMRT) for prostate cancer [3], but that most symptoms resolve within 6 months and long-term quality of life is usually similar to baseline [4]. Good tolerance of prostate cancer radiotherapy in the elderly has been reported in retrospective studies [5], but there is a lack of prospective data.

Adapting oncological treatment to the profile of elderly patients remains a challenge. Geriatric screening tools have been developed to orient frail patients before any oncologic intervention [6], but comprehensive geriatric assessment (CGA) provides a more accurate evaluation. Although CGA is common prior to surgery, chemotherapy [7], or ADT [8], specific studies on prostate cancer radiotherapy in elderly patients have mostly been retrospective, lacking in accurate geriatric evaluation [9], or have focused on toxicity (physician-reported) rather than quality of life (self-reported) [10]. Our study was designed to address this gap and determine whether using CGA is capable of predicting QoL outcomes following radiotherapy for localized prostate cancer in the elderly.

\section{Results}

The study included 230 patients from 11 different cancer centers. Twenty-two patients were excluded from the analysis: One patient was too young (73 years), and quality of life questionnaire were missing for ten patients at the baseline, and for eleven at both two and six months (supplementary material Figure S1). In total, 208 patients were analyzed (Table 1). According to D'Amico's classification, most presented with intermediate- $(42.7 \%)$ or high-risk $(48.6 \%)$ prostate cancer; $47.6 \%$ received concomitant ADT. The median age was 77 years (from 75 to 89). Patients traveled a median of $23 \mathrm{~km}$ (mean $30 \mathrm{~km}$; range 2-147) from their homes to the radiotherapy center. 
Table 1. Patient characteristics $(\mathrm{N}=208)$.

\begin{tabular}{|c|c|c|}
\hline Characteristics & Characteristics & $\mathbf{N}(\%)$ \\
\hline \multirow{3}{*}{ Age } & $75-79$ & $154(74.0)$ \\
\hline & $80-84$ & $49(23.6)$ \\
\hline & $\geq 85$ & $5(2.4)$ \\
\hline \multirow{4}{*}{ BMI } & underweight $(<18)$ & $0(0.0)$ \\
\hline & normal (18-25) & $71(34.6)$ \\
\hline & overweight (25-30) & $94(45.9)$ \\
\hline & obesity $(>30)$ & $40(19.5)$ \\
\hline \multirow{2}{*}{ Number of medications } & $0-3$ & $107(51.4)$ \\
\hline & $>3$ & $109(48.6)$ \\
\hline \multirow{3}{*}{ Distance to radiotherapy center } & $<30 \mathrm{~km}$ & $119(57.2)$ \\
\hline & 30 to $60 \mathrm{~km}$ & $57(27.4)$ \\
\hline & $\geq 60 \mathrm{~km}$ & $32(15.4)$ \\
\hline \multirow{3}{*}{ Clinical stage } & low & $18(8.7)$ \\
\hline & Intermediate & $88(42.7)$ \\
\hline & high & $100(48.6)$ \\
\hline \multirow{2}{*}{ Radiotherapy } & prostate & $185(88.9)$ \\
\hline & prostate bed & $23(11.1)$ \\
\hline \multirow{2}{*}{ ADT } & yes & $99(47.6)$ \\
\hline & no & $109(52.4)$ \\
\hline
\end{tabular}

BMI: body mass index; ADL: activities of daily living; IADL: instrumental activities of daily living; ADT: androgen deprivation therapy.

\subsection{Urinary and Geriatric Impairment Over Time}

Before radiotherapy, $2.5 \%$ of patients (5/200) suffered from severely (International Prostate Symptom Score (IPSS) 20-35) impaired urinary function, and 4.4\% (8/182) did at 6 months. Function was moderately impaired (IPSS 8-19) in 38.5\% (77/200) of patients before radiotherapy and in $37.9 \%$ (69/182) at six months (Table 2).

Table 2. Urinary and geriatric impairments over time.

\begin{tabular}{ccc}
\hline Geriatric problems & M0 N = 208 (\%) & M6 N = 208 (\%) \\
\hline Depression & $48(23)$ & $47(22.6)$ \\
Impaired GUAGT & $17(8.2)$ & $16(7.7)$ \\
Malnutrition & $1(0.5)$ & $1(0.5)$ \\
Comorbidities & $134(64.5)$ & $135(64.9)$ \\
ADL impairment & $26(12.5)$ & $26(12.5)$ \\
IADL impairment & $34(16.3)$ & $32(11.1)$ \\
Cognitive impairment & $48(23)$ & $53(25.5)$ \\
\hline Urinary function (IPSS score) & M0 N = 200 (\%) & M6 N = 182 (\%) \\
\hline Severely impaired (IPSS 20-35) & $5(2.5)$ & $89(4.4)$ \\
Moderately impaired (IPSS 8-19) & $77(38.5)$ & $105(57.7)$ \\
Mildly impaired or normal & $118(59)$ & \\
function (IPSS <8) & &
\end{tabular}

GUAGT: Get Up And Go Test; ADL: activities of daily living; IADL: instrumental activities of daily living; IPSS: International Prostate Symptom Score; M0: study entry, before radiotherapy; M6: six months after radiotherapy.

The Cumulative Illness Rating Scale for Geriatrics (CIRS-G) revealed some degree of comorbidity in $64.5 \%$ of patients; at least one severe comorbidity (i.e., at least one organ system with grade 3-4 comorbidity) was present in $28.2 \%$ of patients at baseline and in $64.9 \%$ at 6 months. A Geriatric Depression Scale (GDS) score $\geq 1$ highlighted depressive symptoms in 48 patients (23\%) before 
treatment, and 47 patients $(22.6 \%)$ at six months. Before treatment, the activities of daily living (ADL score $>6$ ) and the instrumental activities (Instrumental Activities of Daily Living (IADL) $>7$ ) were compromised in $26(12.5 \%)$ and 34 (16.3\%) patients, respectively. At 6 months, they were impaired in 26 $(12.5 \%)$ and $32(11.1 \%)$ patients, respectively. Forty-eight (23.1\%) patients presented cognitive disorders (Mini Mental State Examination (MMSE) < 27) before treatment and $53(25.5 \%)$ after 6 months. The assessed risk of fall (Get Up And Go Test (GUAGT) < 0) was 8.2\% before and 7.7\% after radiotherapy, and undernutrition (Mini Nutritional Assessment (MNA) $\leq 17$ ) was found in one patient.

\subsection{Evolution in Quality of Life}

Patient-reported QoL following radiotherapy is shown in Figure 1 (individual data). For 182 patients, the QLQ C30 questionnaire was available before treatment and at 6 months. According to this questionnaire, at 6 months, a moderate decrease in general QoL (loss of 10 to 20 points) was found in 29 patients $(16 \%)$ and a marked one ( $\geq 20$ points) in another 16 patients $(8.8 \%)$. The most frequent QoL alterations were fatigue (64 patients), role functioning (46), pain (43), cognitive functioning (41), and physical functioning (40).

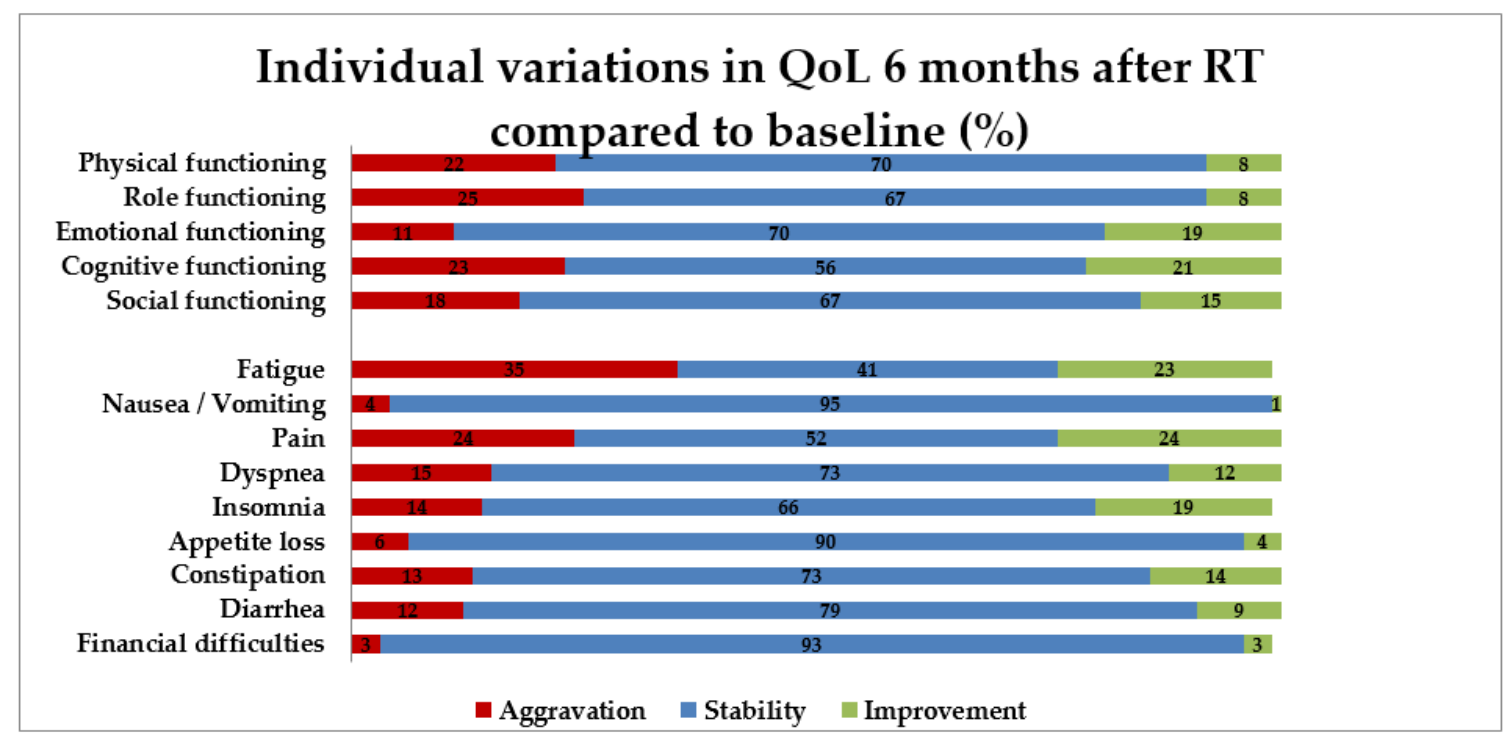

Figure 1. Individual variations in quality of life six months after radiotherapy compared to baseline.

QoL: quality of life; RT: radiotherapy.

Figure 2 shows the evolution over time of each item on the QLQ C30 questionnaire (mean comparisons between baseline, and two and six months). At two months, we found a significant $(p<0.01)$ decrease in physical (mean loss $-3, p=0.0001)$, role (mean loss $-9, p<0.0001$ ), and social (mean loss $-3, p=0.007$ ) functioning. For symptoms, changes in fatigue (mean increase $+7, p<0.0001$ ) and diarrhea (mean increase $+6, p=0.003$ ) were significant at two months. Only physical and role functioning remained significantly impaired at six months (mean loss -3 and $-7, p=0.0001$ and $p<0.0001$, respectively). 
a

Functional dimensions over time

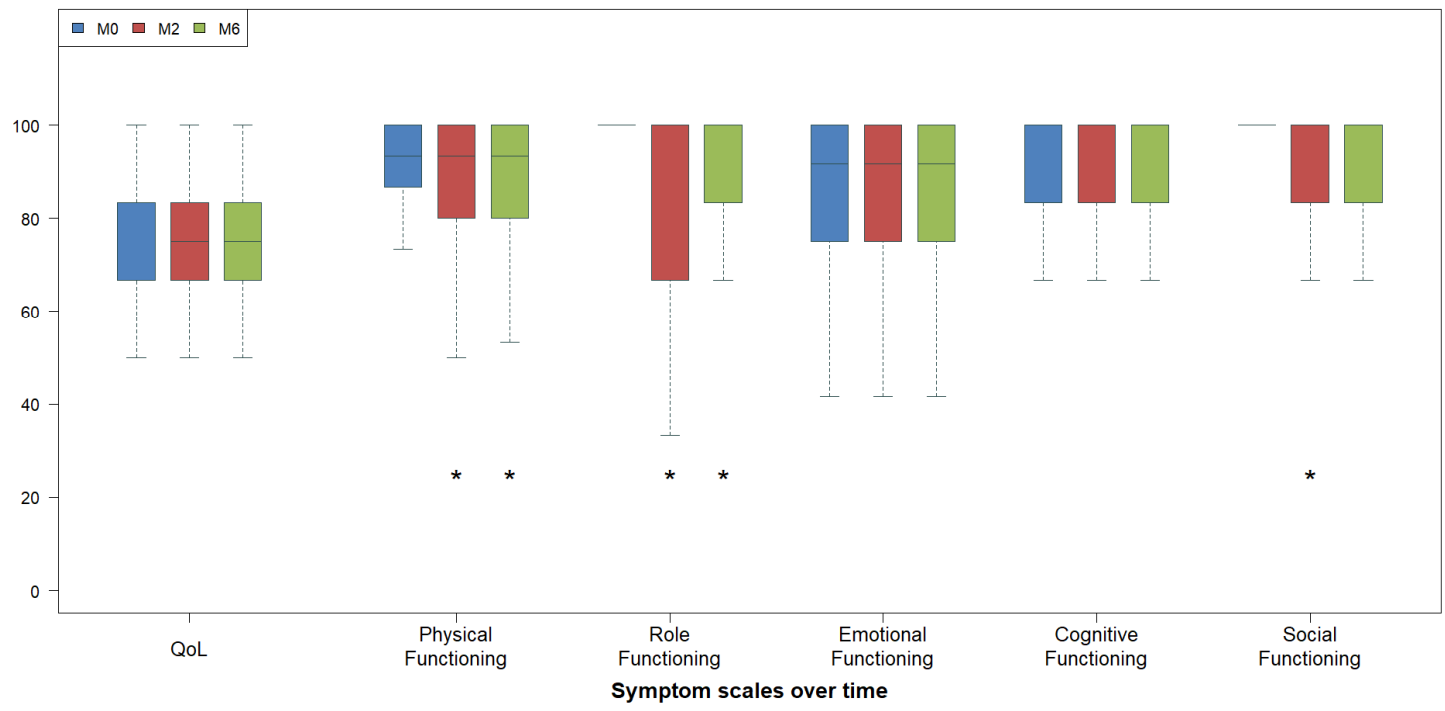

b

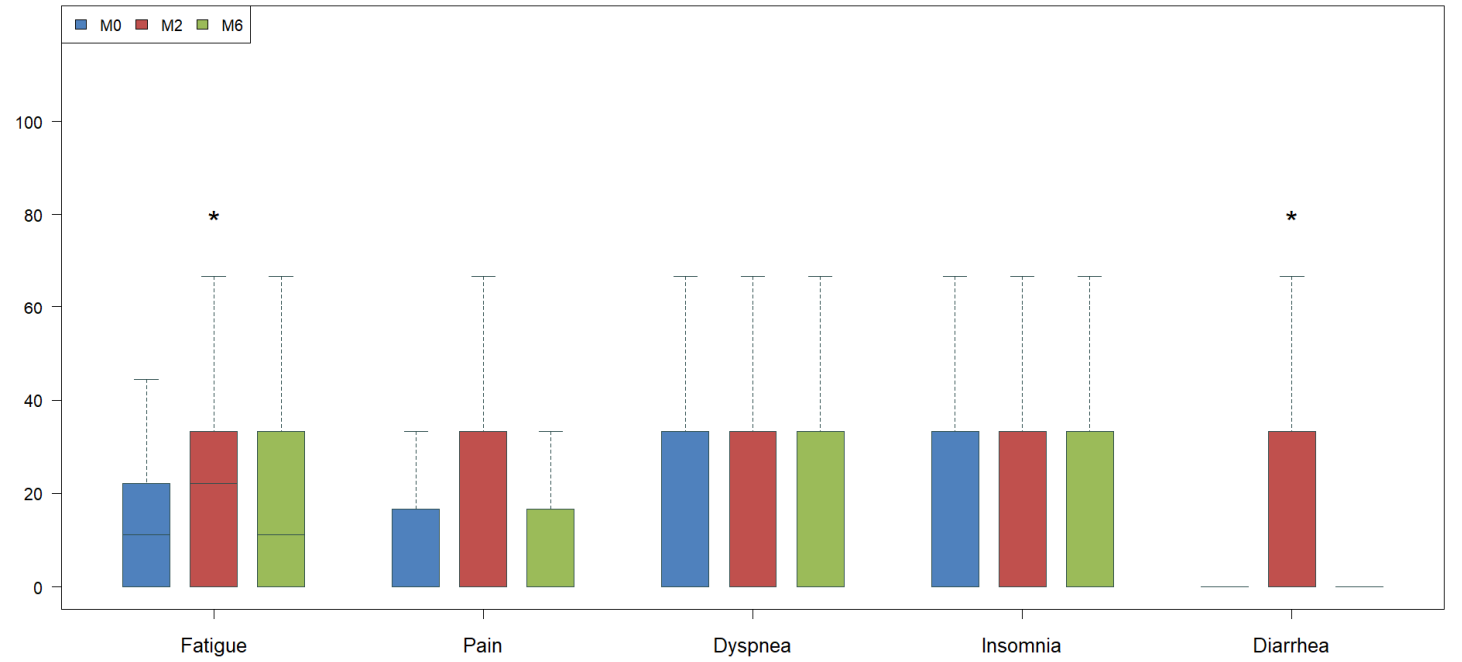

Figure 2. Quality of life over time (means comparison). For each item in the QLQ C30 questionnaire, we compared mean scores before, and two and six months after, radiotherapy. For the functional scales (a), higher scores represented better QoL. For the symptom scores (b), higher scores represented more severe symptoms and worse QoL. *Statistically significant variations $(p<0.05)$. For symptom scales, items without any variations (nausea, appetite loss, constipation, and financial difficulties) have not been represented to make the figure easier to read.

\subsection{Predictive Factors for Qol Impairment}

The aim of our study was to use initial clinical or geriatric settings to identify the patients at risk of QoL impairment after prostate cancer radiotherapy. Unfortunately, we found no external parameter capable of predicting a significant decrease in general QoL. Only QoL deterioration at two months was correlated with worsening QoL six months after prostate cancer radiotherapy $(p=0.023)$ (Table 3). 
Table 3. Predictive factors for changes $\geq 10$ points in quality of life scores at M6/M0.

\begin{tabular}{|c|c|c|c|c|}
\hline Predictive Factors & Predictive Factors & $\begin{array}{l}\text { No QoL Decrease } \\
\quad(n=136)\end{array}$ & $\begin{array}{l}\text { QoL Decrease } \\
\quad(n=45)\end{array}$ & $p$ \\
\hline Age (+/- SD) & & $78.1(+/-2.5)$ & $78.2(+/-2.9)$ & 0.779 \\
\hline Distance (+/- SD) & & $29.9(+/-24.9)$ & $31.9(+/-23.7)$ & 0.638 \\
\hline $\mathrm{BMI}(+/-\mathrm{SD})$ & & $26.6(+/-3.9)$ & $27.9(+/-5.5)$ & 0.098 \\
\hline Number of medications (+/-SD) & & $3.3(+/-2.6)$ & $2.9(+/-2.2)$ & 0.429 \\
\hline \multirow{3}{*}{ QoL decrease at M2 } & $<10$ & 95 & 21 & \\
\hline & $\geq 10$ & 30 & 17 & 0.023 \\
\hline & Low & 13 & 2 & \\
\hline \multirow[t]{2}{*}{ Clinical stage at M0 } & Intermediate & 64 & 16 & \\
\hline & High & 57 & 27 & 0.114 \\
\hline \multirow{3}{*}{ Radiotherapy } & prostate & 102 & 36 & \\
\hline & prostatic bed & 13 & 7 & \\
\hline & pelvis & 21 & 2 & 0.106 \\
\hline \multirow{2}{*}{ ADT } & No & 78 & 20 & \\
\hline & Yes & 58 & 25 & 0.167 \\
\hline \multirow{2}{*}{ Depression at M0 } & No & 106 & 35 & \\
\hline & Yes & 30 & 10 & 0.982 \\
\hline \multirow{2}{*}{ Risk of fall at M0 } & No & 108 & 38 & \\
\hline & Yes & 9 & 5 & 0.528 \\
\hline \multirow{2}{*}{ Malnutrition at M0 } & No & 135 & 45 & \\
\hline & Yes & 1 & 0 & 0.999 \\
\hline \multirow{2}{*}{ Comorbidities at M0 } & No $:<4$ & 32 & 16 & \\
\hline & Yes :4+ & 88 & 27 & 0.193 \\
\hline \multirow{3}{*}{ Comorbidities gr3-4 at M0 } & 0 & 85 & 32 & \\
\hline & 1 or more & 35 & 11 & 0.654 \\
\hline & Light & 74 & 29 & \\
\hline \multirow[t]{3}{*}{ Urinary symptoms at M0 } & Moderate & 51 & 15 & \\
\hline & High & 5 & 0 & 0.368 \\
\hline & Mild & 54 & 19 & \\
\hline \multirow[t]{2}{*}{ Urinary symptoms at M2 } & Moderate & 60 & 15 & \\
\hline & Severe & 11 & 1 & 0.367 \\
\hline \multirow{2}{*}{ ADL impairments at M0 } & No & 119 & 39 & \\
\hline & Yes & 16 & 6 & 0.793 \\
\hline \multirow{2}{*}{ IADL impairments } & No & 117 & 36 & \\
\hline & Yes & 18 & 9 & 0.278 \\
\hline \multirow{2}{*}{ Cognitive impairment } & No & 108 & 34 & \\
\hline & Yes & 28 & 11 & 0.585 \\
\hline
\end{tabular}

BMI: body mass index; QoL: quality of life; M0: study entry, before radiotherapy; M2/M6: two/six months after radiotherapy; ADT: androgen deprivation therapy; ADL: activities of daily living; IADL: instrumental activities of daily living.

\section{Discussion}

Identifying which elderly patients will benefit from local treatment for prostate cancer is still a challenge, and prospective studies on QoL after radiotherapy in this population were lacking. Our exhaustive and systematic documentation of CGA before and six months after treatment, has, to the best of our knowledge, created a unique dataset.

The purpose of this study was to collect a significant amount of data (relating to the patients, their tumors and specific geriatric characteristics) and to determine which could predict a decrease in QoL after radiotherapy. However, neither initial geriatric assessment items, oncologic data, distance to radiotherapy center, nor adding a concomitant ADT to radiotherapy could be associated with impaired QoL at six months. This may be explained by several factors.

First, the initial CGA may have identified impairments, and in turn, corrective measures, that may have contributed to improved tolerance. This potential bias was identified during the study design process, but to failure to implement these corrective measures once the impairment had been identified 
would have been unethical. Secondly, the number of patients in our study who experienced decreased QoL was limited. One study that reported higher levels of comorbidity did find that comorbidity was predictive of impaired long-term QoL after prostate cancer radiotherapy associated with ADT [11]; another, like this study, found no CGA parameter that was predictive for significant radiotherapy toxicity [10]. It is possible that the G8 and CGA tools are poorly-adapted to radiotherapy and localized cancer [12], having been principally developed for chemotherapy or major surgery [13,14]. Several studies have emphasized the determinativeness of nutritional status before treatment on the smooth running of chemotherapy, and even on survival $[13,15]$. That is why, on the G8 (validated geriatric screening questionnaire), nutrition assessment has prominence (three questions out of eight). On the other hand, undernutrition was practically absent from our study. Similarly, geriatricians usually give importance to the risk of falls as a mark of fragility [13] but fewer than $10 \%$ of our patients were found to be at high risk of falling. This suggested that screening tools such as the G8 seem ill-suited to detecting vulnerabilities in this particular population, but even with the fuller CGA used in our study, we failed to predict tolerance of radiotherapy [10]. The development and evaluation of new tools are needed.

Despite many geriatric frailties and several comorbidities before treatment, $75 \%$ of our patients had maintained or improved their overall QoL at study completion. As our study population seemed representative of the routine clinical elderly prostate cancer population, we suggest that earlier fears of radiotherapy toxicity in this group may have been overemphasized. Our baseline CGA showed that most patients had numerous fragilities. Two thirds of the patients in our study presented with comorbidities, sometimes severe (28.2\%), which may affect the tolerance of ADT. Unsuspected cognitive disorders and depression were highlighted in nearly $20 \%$ of patients, which may also be aggravated by ADT [16]. In addition, one in six patients suffered from a loss of autonomy.

Transient acute toxicity was observed in certain patients. Severe urinary symptoms were present in $2.5 \%$ of patients at the baseline, compared with $4.4 \%$ at 6 months, with a peak of $7.5 \%$ at 2 months. Previous studies have found that late urinary toxicity is more frequent in elderly patients $(>70)[17,18]$. Similarly, diarrhea was significantly increased at 2 months but returned to the baseline level at 6 months in our study. Other authors have shown that older patients are also at higher risk of digestive toxicity $[19,20]$. Radiotherapy also temporarily increased fatigue, with possible consequences for social and leisure interactions. There are many potential causes of asthenia during radiotherapy: ADT, nocturia, comorbidities, or trips to the cancer center may all contribute. Fatigue is frequent in men undergoing radiotherapy for prostate cancer, especially among those treated with concomitant ADT [21,22], but whether this symptom is more pronounced in elderly patients remains debated.

Despite acute toxicity, overall QoL was maintained or improved in $71 \%$ of patients at 2 months and $75 \%$ at 6 months. Only $8.8 \%$ of patients had severely decreased QoL at six months (> 20 points). Our good results are consistent with data found in younger patients, in whom short-term ADT associated with radiation therapy did not greatly impair physical or mental health in comparison with active monitoring [23]. We previously published a longitudinal evaluation of QoL after intensity-modulated prostate radiotherapy in younger subjects (age range 50-80 years, median age 73) and found consistent results: quality of life at six months was generally similar to the baseline after temporary impairment at two months [3,4]. Other authors have also reported a moderate but transient impaired QoL after radiotherapy in younger patients [24]. Although a direct comparison has not been scientifically validated, we note that $25 \%$ of patients in this geriatric series experienced a 6-month QoL decrease versus $15.8 \%$ in our series with younger patients. The impact of age on the tolerability of radiotherapy remains an open question.

Our uniquely exhaustive CGA before and six months after treatment found that geriatric parameters appeared stable over time, except for cognitive impairment. This suggests that prostate cancer radiotherapy does not reduce patient autonomy or mood, which are major elements in quality of life and independent daily living in the elderly. Cognitive impairment, present in $23 \%$ of patients 
before treatment and $25.5 \%$ after 6 months, may be related to ADT [25] but this remains open for debate [26].

Too many patients are currently offered only ADT, having been judged arbitrarily as too old or frail for radiotherapy, without rigorous geriatric evaluation [27]. We have shown that QoL is mainly preserved or improved after prostate cancer radiotherapy, even in the presence of impaired geriatric parameters, and believe that patients should be offered the most effective oncological treatment based on geriatric evaluation.

Our study may have some limitations. First, we tried to minimize the selection bias through the multicentric nature of this study, not limited to teaching hospitals. Beyond the age of 75 years, radical prostatectomy is not recommended because of the higher risk of urinary toxicity than in younger patients [28]. In our study, only 23 patients $(11.1 \%)$ were treated with post-operative radiotherapy. It is conceivable that this operated subpopulation may have lower comorbidities as it had previously been considered eligible for prostatectomy. However, in the majority of cases, prostatectomy was performed several years earlier with a biochemical relapse that occurred after the age of 75 years. Post-operative versus exclusive radiotherapy was not predictive for a different quality of life after treatment in our study. In addition, the high number of patients with frailties according to the initial CGA was indicative of the reasonably representative nature of our population.

Second, this study focused on acute toxicity and early evaluation of QoL. In geriatric populations, with shorter life expectancy than younger patients, the rapid restoration of quality of life seemed all the more important to us. Furthermore, we have previously shown that QoL, after temporarily worsening, returned to the baseline between 6 and 18 months after the end of radiotherapy. However, our results need to be confirmed after a longer follow-up period, knowing that digestive toxicities can appear several years after the end of the treatment [23].

The great originality of our study is its extensive and prospective geriatric evaluation, carried out prior to treatment and renewed at 6 months.

\section{Patients and Methods}

The inclusion criteria for our prospective, multicenter cohort study (NCT 02876237) were as follows: men aged 75 or more, with localized prostate cancer, and a proposal for radiation therapy (multidisciplinary tumor board) with curative intent, either alone or combined with ADT. The appropriate French ethics committees approved the study (number 2014-A00300-47), and all patients gave consent for participation. A detailed description of the study methods has been published previously [29].

In this study, we assessed QoL at 2 months because this period corresponds to acute side effects. We selected a later time point because acute side effects resolved within 6 months in our previous study [4].

The patients completed 3 questionnaires before radiotherapy, and at two and six months after treatment: the International Prostate Symptom Score (IPSS), the International Index of Erectile Function (IIEF-5), and the European Organization for Research and Treatment of Cancer (EORTC) quality of life (QLQ C30 version 3.0). Items were combined according to EORTC criteria into several scales ranging from 1 to 100. Higher scores for global health and function indicate better quality of life (QoL); higher symptom scores indicate poorer QoL. A geriatrician performed a comprehensive geriatric assessment prior to radiotherapy and six months after. This CGA included current medication, body mass index, home to study center distance, the Cumulative Illness Rating Scale for Geriatrics (CIRS-G), activities of daily life (ADL), instrumental activities of daily life (IADL), Mini-Mental State Examination (MMSE), Mini Geriatric Depression Scale (GDS), Mini Nutritional Assessment (MNA), and the Get Up And Go Test (GUAGT).

The primary endpoint was to identify the predictive factors for impaired QoL after radiotherapy, defined as a decrease in overall QLC30 score of more than 10 points at 2 or 6 months compared with 
baseline. Secondary endpoints were to report toxicity (urinary and sexual functions) and evolution in geriatric parameters (CGA) over time.

Predictive factors for QoL variations (impact of tumor characteristics, treatment, or CGA parameters) were screened for using the Fisher test (categoric variables) or the Mann and Whitney test (continuous variables). The Wilcoxon test was used to analyze evolution in QoL parameters from the baseline. The significance threshold was $p<0.05$, except for changes in QoL over time $(p<0.01)$. A clinically relevant change in QoL was defined as a $>10$-point change [30,31].

We expected approximately $25 \%-30 \%$ of patients to have a $>10$-point decrease in overall QoL (29-30 items of QLQ C30 scale). We chose the Severity Index Score (from CIRS-G, which evaluates comorbidities) as a representative geriatric scale because in current daily clinical practice, in elderly patients, comorbidities seem to be the main criterion of choice between palliative (ADT) and curative treatment (radiotherapy). We expected about $25 \%$ of patients to be classified with a high Severity Index Score $(>2)$.

We expected that patients with a Severity Index Score of $>2$ would more often have a $>10$-point decrease in QoL ( $40 \%$ vs. $20 \%$, OR $=2.67$ ).

In order to dispose of at least $80 \%$ power to detect such an OR value with alpha risk $=5 \%$ (one-sided), we had to include at least 184 evaluable patients.

\section{Conclusions}

We did not find any predictors of declining quality of life following radiotherapy. Despite numerous comorbidities and geriatric fragilities in our population, QoL mostly appeared to be maintained or improved after radiotherapy, with or without ADT. These data suggest that the fear of an iatrogenic decrease in QoL should not result in abandoning a curative treatment that is likely to improve the life expectancy of these patients. Moreover, performing an extensive CGA prior to treatment can reveal unsuspected frailties that can worsen during or after treatment, but also and more importantly provides an opportunity for them to be managed appropriately. Further evaluation of long-term QoL and geriatric assessments to refine the prediction of tolerance of radiotherapy are needed.

Supplementary Materials: The following are available online at http://www.mdpi.com/2072-6694/12/3/635/s1, Figure S1: Flow chart.

Author Contributions: Conceptualization, A.G. (Aurore Goineau) and S.S.; methodology, L.C.; software, A.G. (Aurore Goineau); validation, A.G. (Aurore Goineau) and S.S.; formal analysis, A.G. (Aurore Goineau); investigation, A.G. (Aurore Goineau), J.-M.C., B.V., A.G. (Agnès Ghesquière), G.B., D.J., N.M., X.A., J.C., P.B., G.C., E.D.-A., X.B., Y.B., M.D., L.D.D. and S.S.; resources, S.S.; data curation, L.C.; writing-original draft preparation, A.G. (Aurore Goineau); writing - review and editing, S.S.; visualization, S.S.; supervision, S.S.; project administration, A.G. (Aurore Goineau) and S.S.; funding acquisition, A.G. (Aurore Goineau). All authors have read and agree to the published version of the manuscript.

Funding: This research was funded by Unité de Coordination en Onco-Gériatrie (UCOG) des Pays-de-la-Loire, grant number 0 .

Acknowledgments: Funded by the Unité de Coordination en Onco-Gériatrie (UCOG) des Pays-de-la-Loire.

Conflicts of Interest: The authors declare no conflict of interest. The funders had no role in the design of the study; in the collection, analyses, or interpretation of data; in the writing of the manuscript, or in the decision to publish the results.

\section{References}

1. Bechis, S.K.; Carroll, P.R.; Cooperberg, M.R. Impact of age at diagnosis on prostate cancer treatment and survival. J. Clin. Oncol. 2011, 29, 235-241. [CrossRef]

2. Bekelman, J.E.; Mitra, N.; Handorf, E.A.; Uzzo, R.G.; Hahn, S.A.; Polsky, D.; Armstrong, K. Effectiveness of androgen-deprivation therapy and radiotherapy for older men with locally advanced prostate cancer. J. Clin. Oncol. 2015, 33, 716-722. [CrossRef] 
3. Marchand, V.; Bourdin, S.; Charbonnel, C.; Rio, E.; Munos, C.; Campion, L.; Bonnaud-Antignac, A.; Lisbona, A.; Mahé, M.-A.; Supiot, S. No impairment of quality of life 18 months after high-dose intensity-modulated radiotherapy for localized prostate cancer: A prospective study. Int. J. Radiat. Oncol. Biol. Phys. 2010, 77, 1053-1059. [CrossRef]

4. Goineau, A.; Marchand, V.; Rigaud, J.; Bourdin, S.; Rio, E.; Campion, L.; Bonnaud-Antignac, A.; Mahé, M.-A.; Supiot, S. Prospective evaluation of quality of life 54 months after high-dose intensity-modulated radiotherapy for localized prostate cancer. Radiat. Oncol. 2013, 8, 53. [CrossRef]

5. Nguyen, T.D.; Azria, D.; Brochon, D.; Poortmans, P.; Miller, R.C.; Scandolaro, L.; Majewski, W.; Krengli, M.; Abacioglu, U.; Moretti, L.; et al. Curative external beam radiotherapy in patients over 80 years of age with localized prostate cancer: A retrospective rare cancer network study. Crit. Rev. Oncol. Hematol. 2010, 74, 66-71. [CrossRef]

6. Soubeyran, P.; Bellera, C.; Goyard, J.; Heitz, D.; Curé, H.; Rousselot, H.; Albrand, G.; Servent, V.; Jean, O.S.; van Praagh, I.; et al. Screening for vulnerability in older cancer patients: The ONCODAGE Prospective Multicenter Cohort Study. PLoS ONE 2014, 9, e115060. [CrossRef]

7. Gerritse, F.L.; Meulenbeld, H.J.; Roodhart, J.M.L.; van der Velden, A.M.T.; Blaisse, R.J.B.; Smilde, T.J.; Erjavec, Z.; de Wit, R.; Los, M. NePro Study Investigators Analysis of docetaxel therapy in elderly ( $\geq 70$ years) castration resistant prostate cancer patients enrolled in the Netherlands Prostate Study. Eur. J. Cancer 2013, 49, 3176-3183. [CrossRef]

8. Lee, C.E.; Kilgour, A.; Lau, Y.K.J. Efficacy of walking exercise in promoting cognitive-psychosocial functions in men with prostate cancer receiving androgen deprivation therapy. BMC Cancer 2012, 12, 324. [CrossRef]

9. Bekelman, J.E.; Mitra, N.; Efstathiou, J.; Liao, K.; Sunderland, R.; Yeboa, D.N.; Armstrong, K. Outcomes after intensity-modulated versus conformal radiotherapy in older men with nonmetastatic prostate cancer. Int. J. Radiat. Oncol. Biol. Phys. 2011, 81, e325-e334. [CrossRef]

10. Osborne, G.E.C.; Appleyard, S.A.; Gilbert, D.C.; Jones, C.I.; Lorimer, C.; Villanueva, M.; Peasgood, E.; Robinson, A.; Nikapota, A.; Ring, A. Comprehensive Geriatric Assessment in Men Aged 70 Years or Older with Localised Prostate Cancer Undergoing Radical Radiotherapy. Clin. Oncol. 2017, 29, 609-616. [CrossRef]

11. Geinitz, H.; Thamm, R.; Scholz, C.; Heinrich, C.; Prause, N.; Kerndl, S.; Keller, M.; Busch, R.; Molls, M.; Zimmermann, F.B. Longitudinal analysis of quality of life in patients receiving conformal radiation therapy for prostate cancer. Strahlenther. Onkol. 2010, 186, 46-52. [CrossRef]

12. Liuu, E.; Canouï-Poitrine, F.; Tournigand, C.; Laurent, M.; Caillet, P.; Le Thuaut, A.; Vincent, H.; Culine, S.; Audureau, E.; Bastuji-Garin, S.; et al. Accuracy of the G-8 geriatric-oncology screening tool for identifying vulnerable elderly patients with cancer according to tumour site: The ELCAPA-02 study. J. Geriatr. Oncol. 2014, 5, 11-19. [CrossRef]

13. Soubeyran, P.; Fonck, M.; Blanc-Bisson, C.; Blanc, J.-F.; Ceccaldi, J.; Mertens, C.; Imbert, Y.; Cany, L.; Vogt, L.; Dauba, J.; et al. Predictors of early death risk in older patients treated with first-line chemotherapy for cancer. J. Clin. Oncol. 2012, 30, 1829-1834. [CrossRef]

14. Aparicio, T.; Jouve, J.-L.; Teillet, L.; Gargot, D.; Subtil, F.; Le Brun-Ly, V.; Cretin, J.; Locher, C.; Bouché, O.; Breysacher, G.; et al. Geriatric factors predict chemotherapy feasibility: Ancillary results of FFCD 2001-02 phase III study in first-line chemotherapy for metastatic colorectal cancer in elderly patients. J. Clin. Oncol. 2013, 31, 1464-1470. [CrossRef]

15. Blanc-Bisson, C.; Fonck, M.; Rainfray, M.; Soubeyran, P.; Bourdel-Marchasson, I. Undernutrition in elderly patients with cancer: Target for diagnosis and intervention. Crit. Rev. Oncol. Hematol. 2008, 67, $243-254$. [CrossRef]

16. Dinh, K.T.; Reznor, G.; Muralidhar, V.; Mahal, B.A.; Nezolosky, M.D.; Choueiri, T.K.; Hoffman, K.E.; Hu, J.C.; Sweeney, C.J.; Trinh, Q.-D.; et al. Association of Androgen Deprivation Therapy With Depression in Localized Prostate Cancer. J. Clin. Oncol. 2016, 34, 1905-1912. [CrossRef]

17. Wortel, R.C.; Incrocci, L.; Pos, F.J.; van der Heide, U.A.; Lebesque, J.V.; Aluwini, S.; Witte, M.G.; Heemsbergen, W.D. Late Side Effects After Image Guided Intensity Modulated Radiation Therapy Compared to 3D-Conformal Radiation Therapy for Prostate Cancer: Results From 2 Prospective Cohorts. Int. J. Radiat. Oncol. Biol. Phys. 2016, 95, 680-689. [CrossRef] 
18. Cozzarini, C.; Fiorino, C.; Da Pozzo, L.F.; Alongi, F.; Berardi, G.; Bolognesi, A.; Briganti, A.; Broggi, S.; Deli, A.; Guazzoni, G.; et al. Clinical factors predicting late severe urinary toxicity after postoperative radiotherapy for prostate carcinoma: A single-institute analysis of 742 patients. Int. J. Radiat. Oncol. Biol. Phys. 2012, 82, 191-199. [CrossRef]

19. Longobardi, B.; Berardi, G.; Fiorino, C.; Alongi, F.; Cozzarini, C.; Deli, A.; La Macchia, M.; Perna, L.; Di Muzio, N.G.; Calandrino, R. Anatomical and clinical predictors of acute bowel toxicity in whole pelvis irradiation for prostate cancer with Tomotherapy. Radiother. Oncol. 2011, 101, 460-464. [CrossRef]

20. Perna, L.; Alongi, F.; Fiorino, C.; Broggi, S.; Cattaneo Giovanni, M.; Cozzarini, C.; Di Muzio, N.; Calandrino, R. Predictors of acute bowel toxicity in patients treated with IMRT whole pelvis irradiation after prostatectomy. Radiother. Oncol 2010, 97,71-75. [CrossRef]

21. Langston, B.; Armes, J.; Levy, A.; Tidey, E.; Ream, E. The prevalence and severity of fatigue in men with prostate cancer: A systematic review of the literature. Support. Care Cancer 2013, 21, 1761-1771. [CrossRef] [PubMed]

22. Lilleby, W.; Stensvold, A.; Dahl, A.A. Fatigue and other adverse effects in men treated by pelvic radiation and long-term androgen deprivation for locally advanced prostate cancer. Acta Oncol. 2016, 55, 807-813. [CrossRef] [PubMed]

23. Donovan, J.L.; Hamdy, F.C.; Lane, J.A.; Mason, M.; Metcalfe, C.; Walsh, E.; Blazeby, J.M.; Peters, T.J.; Holding, P.; Bonnington, S.; et al. Patient-Reported Outcomes after Monitoring, Surgery, or Radiotherapy for Prostate Cancer. N. Engl. J. Med. 2016, 375, 1425-1437. [CrossRef] [PubMed]

24. Kerleau, C.; Guizard, A.-V.; Daubisse-Marliac, L.; Heutte, N.; Mercier, M.; Grosclaude, P.; Joly, F. French Network of Cancer Registries (FRANCIM) Long-term quality of life among localised prostate cancer survivors: QALIPRO population-based study. Eur. J. Cancer 2016, 63, 143-153. [CrossRef]

25. Gonzalez, B.D.; Jim, H.S.L.; Booth-Jones, M.; Small, B.J.; Sutton, S.K.; Lin, H.-Y.; Park, J.Y.; Spiess, P.E.; Fishman, M.N.; Jacobsen, P.B. Course and Predictors of Cognitive Function in Patients With Prostate Cancer Receiving Androgen-Deprivation Therapy: A Controlled Comparison. J. Clin. Oncol. 2015, 33, 2021-2027. [CrossRef]

26. Alibhai, S.M.H.; Breunis, H.; Timilshina, N.; Johnston, C.; Tomlinson, G.; Tannock, I.; Krahn, M.; Fleshner, N.E.; Warde, P.; Canning, S.D.; et al. Impact of androgen-deprivation therapy on physical function and quality of life in men with nonmetastatic prostate cancer. J. Clin. Oncol. 2010, 28, 5038-5045. [CrossRef]

27. Bratt, O.; Folkvaljon, Y.; Hjälm Eriksson, M.; Akre, O.; Carlsson, S.; Drevin, L.; Franck Lissbrant, I.; Makarov, D.; Loeb, S.; Stattin, P. Undertreatment of Men in Their Seventies with High-risk Nonmetastatic Prostate Cancer. Eur. Urol. 2015, 68, 53-58. [CrossRef]

28. Kopp, R.P.; Marshall, L.M.; Wang, P.Y.; Bauer, D.C.; Barrett-Connor, E.; Parsons, J.K. Osteoporotic Fractures in Men (MrOS) Research Group The burden of urinary incontinence and urinary bother among elderly prostate cancer survivors. Eur. Urol. 2013, 64, 672-679. [CrossRef]

29. Goineau, A.; Campion, L.; d'Aillières, B.; Vié, B.; Ghesquière, A.; Béra, G.; Jaffres, D.; de Laroche, G.; Magné, N.; Artignan, X.; et al. Comprehensive Geriatric Assessment and quality of life after localized prostate cancer radiotherapy in elderly patients. PLoS ONE 2018, 13, e0194173. [CrossRef]

30. Osoba, D.; Rodrigues, G.; Myles, J.; Zee, B.; Pater, J. Interpreting the significance of changes in health-related quality-of-life scores. J. Clin. Oncol. 1998, 16, 139-144. [CrossRef]

31. Guren, M.G.; Dueland, S.; Skovlund, E.; Fosså, S.D.; Poulsen, J.P.; Tveit, K.M. Quality of life during radiotherapy for rectal cancer. Eur. J. Cancer 2003, 39, 587-594. [CrossRef]

(C) 2020 by the authors. Licensee MDPI, Basel, Switzerland. This article is an open access article distributed under the terms and conditions of the Creative Commons Attribution (CC BY) license (http://creativecommons.org/licenses/by/4.0/). 